\title{
Is the different time trend (1997-2008) of the obesity prevalence among adults in the three Belgian regions associated with lifestyle changes?
}

\author{
Sabine Drieskens*, Johan Van der Heyden, Stefaan Demarest and Jean Tafforeau
}

\begin{abstract}
Background: Obesity is a major public health issue with increasing prevalence among adults. However, in Belgium the regional time trends (1997-2008) differed: the prevalence of obesity increased in the Flemish and Brussels Regions, but remained stable in the Walloon Region, the latter still showing the highest prevalence. The purpose of the present study is to explore if the different time trends of obesity prevalence in the three Belgian regions is associated with lifestyle changes.

Methods: We used data from four successive cross-sectional waves (1997, 2001, 2004 and 2008) of the Belgian Health Interview Survey. The study was restricted to the adult population, resulting in samples of respectively 8,071, 9,391, 10,319 and 8,831 individuals. In line with the WHO definition, obesity was defined as having a BMI $\geq 30$. Differences in regional trends of obesity were investigated through stratified analyses. The association between obesity and survey year, adjusted for lifestyle factors (alcohol consumption, smoking, fruit and vegetables consumption and leisure time physical activity), was assessed via logistic regression models. Interactions were added to the models to explore if the association between lifestyle factors and obesity varied over time.

Results: Obesity was associated with daily alcohol use in the Brussels (OR 0.66, 95\% Cl 0.50-0.88) and Walloon Regions (OR 0.8, 95\% Cl 0.6-0.9), with lower tendencies of being obese for daily drinkers. The probability of being obese was lower among smokers in the Flemish (OR 0.7, 95\% Cl 0.6-0.8) and Walloon Regions (OR 0.7, 95\% Cl 0.6-0.9) than among non-smokers. A lack of leisure time physical activity was associated with the probability of being obese in all regions (Brussels Region: OR 1.6, 95\% Cl 1.3-1.8; Flemish Region: OR 1.6, 95\% Cl 1.4-1.9; Walloon Region: OR 1.8, 95\% CT 1.6-2.1). This association decreased significantly between 1997 and 2008 only in the Walloon Region.
\end{abstract}

Conclusion: The decreasing association between obesity and a lack of leisure time physical activity in the Walloon Region between 1997 and 2008 could indicate that there is an increasing awareness of risk factors for obesity in the Walloon population, which may have resulted in a more favourable evolution of the obesity epidemic.

Keywords: Health Interview Survey, Obesity, Lifestyle, Physical activity, Eating habits, Smoking, Alcohol drinking, Time trend, Health promotion, Belgium

\section{Background}

Obesity is a major public health issue, not only because it has a negative impact on the quality of life [1-3], but also because it is an important risk factor for serious chronic conditions (cardiovascular diseases, type 2 diabetes, some cancers,...) and premature deaths $[1,2,4,5]$. According to

\footnotetext{
* Correspondence: sabine.drieskens@wiv-isp.be

Scientific Institute of Public Health, Operational Direction Public Health and Surveillance, Unit Surveys, Lifestyle and Chronic Conditions, Brussels, Belgium
}

the World Health Organization (WHO), obesity is an 'escalating epidemic' [6]. Over the past decades, the prevalence of obesity among adults has increased in both developed and developing countries [1,7-12].

This was also the case for Belgium. Results from the Belgian Health Interview Surveys (HIS) revealed a linear increase of almost $28 \%$ of the national prevalence of obesity between 1997 and 2008 [13]. This national increase concealed important regional disparities. The Flemish and 
Brussels Regions shared a similar increase of obesity, whereas the Walloon Region remained stable at the relatively high level. This is particularly interesting, because each region has its own public health authority managing the health promotion and preventive care, although linking this to the different regional trends in obesity is not based on evidence but on speculations.

Obesity results from an imbalance between dietary intakes and energy expenditure through physical activity $[14,15]$. When there is a higher calorie intake through food or drinks than is burned, then the energy balance leans towards a weight gain. The WHO has identified counteracting obesity as one of the priority areas of public health action [16]. Obesity is a serious risk factor, which is largely preventable through lifestyle changes [17].

Unhealthy diet and physical inactivity, have been identified as causative factors of obesity, and are themselves consequences of social changes and economic development $[12,18]$. Unhealthy diet habits are partly due to an overconsumption of cheap energy dense food, eating more frequently, dining out, increased portion size (in restaurants and food packages), but also to the rising cost of healthy foods compared to unhealthy foods $[11,19]$. Simultaneously, the introduction of new technologies has influenced people's occupation and daily activities with a decrease of physical activities. In addition, people rely more on motorised transport and spend more of their leisure time doing sedentary activities, such as watching television, playing video games and using the computer $[11,18,20]$. Studies show a positive association between obesity and leisure time physical activity: the prevalence of obesity declines as the amount of leisure time physical activity increases [21-23].

In addition to diet $[3,5,19]$ and physical activity $[3,5,19,23,24]$, alcohol consumption and tobacco use [2] could also be lifestyle factors that would impact the prevalence of obesity. The high energy content of alcohol makes its consumption a potential contributor. A high consumption of alcohol (more than 3 alcoholic drinks per day, with one drink being equivalent to $10 \mathrm{~g}$ of ethanol) is associated with the risk of abdominal obesity in men [25]. Contrarily, smoking and obesity are inversely related. Although the body weight among smokers is lower than among non-smokers, heavy smokers are more obese than moderate smokers, probably as a consequence of other risk behaviours, such as low physical activity, poor diet and a greater alcohol intake [26,27].

The purpose of the present study is to explore if the different time trends of obesity prevalence in the three Belgian regions is associated with lifestyle changes. More specifically, it will be assessed if the different time trends are still observed after adjustment for the four selected lifestyle factors and if their association with obesity has changed over time in all regions.

\section{Methods}

The Belgian Health Interview Survey (HIS) is a periodical cross-sectional study, having been conducted in 1997, 2001, 2004 and 2008. The fieldwork of the fifth survey began in 2013. A representative sample of the Belgian population was selected including all persons residing in Belgium with no restrictions on age or nationality. Quarterly updates of the National population Registry were used as the sampling frame. A multistage clustered sampling design was applied involving a geographical stratification, a selection of municipalities within provinces, of households within municipalities, and of respondents within households. Using matched substitution of nonparticipating households assured the creation of the predefined net-sample size and composition. The basic methodology has been described by Demarest et al. [28]. The overall response rate varied between 55\% and $61 \%[13]$.

Data were collected through a face-to-face interview using PAPI (Paper and Pencil Interviewing) at the participant's home. The interviews were supplemented with a self-administered questionnaire (for the participants aged $15+)$ covering more sensitive topics including mental health, alcohol consumption and sexual behaviour [29]. The questionnaires included existing validated instruments when possible. The survey was carried out in line with the Belgian privacy legislation and approved by an ethical committee.

The Body Mass Index $\left(\mathrm{BMI}=\mathrm{kg} / \mathrm{m}^{2}\right)$ is the most commonly used index of relative weight among adults $[1,8]$. The analysis in this study was restricted to adults aged 18 years and older. According to the recommendation of the WHO, adult individuals, both women and men, with a $\mathrm{BMI} \geq 30$ were considered as obese [6]. The study population consisted of 8,071, 9,391, 10,319 and 8,831 individuals in respectively 1997, 2001, 2004 and 2008. Questions on height and weight were included in the face-to-face questionnaire with the following wording: 'How tall are you without shoes? (cm)' and 'How much do you weight without clothes and shoes? (Kg)'. Pregnant women were asked to report their weight before pregnancy.

The four lifestyle factors selected in this study were based on their relevance and the availability of the data in the HIS during the four surveyed years. For the statistical analysis, these lifestyle factors were recoded as dichotomous indicators:

1. 'daily alcohol drinking' (AL) was in 1997, 2001 and 2004 derived from 4 questions, whereby a subdivision between weekdays and weekend days was made (validated WHO questions). First it was asked if people drink during weekdays. If so, the number of days was asked. The same was applied for the weekend days. This was not the case in 2008. 
Only one general question was asked (validated question, recommended by Eurostat): 'During the past 12 months, how often have you had alcoholic drinks of any kind (beer, wine, cider, spirits, cocktails, premixes, liquor, homemade alcohol...)?', with response categories 1) Every day or almost, 2) 5-6 days a week, 3) 3-4 days a week, 4) 1-2 days a week, 5) 2-3 days in a month, 6) Once a month, 7) Less than once a month, 8) Not in the past 12 months, as I no longer drink alcohol and 9) Never, or only a few sips or trials in my whole life. The response categories were recoded in two groups: daily drinkers versus all other categories;

2. 'current smokers' (TA) was based on a combination of two questions: a) a filter question (only used in 2004 and 2008) 'Have you smoked at least 100 cigarettes (about 5 packets) or the equivalent amount of tobacco in your entire life?' (response categories: 1) yes and 2) no) and b) the validated WHO question (in 2008 slightly adapted to the guidelines of Eurostat) 'Do you (now) smoke (at all nowadays)?' (response categories: 1) Yes, daily, 2) Yes, occasionally and 3) Not at all). People who have smoked less than 100 cigarettes (first question) are not considered as 'current smokers' (no $=2$ ), and those who have smoked that amount or more are considered as ever-smokers. 'Current smokers' (yes $=1$ ) are those who smoke daily and those who smoke occasionally (response categories 1 and 2 of the second question) among the ever-smokers;

3. 'daily consumption of fruit and vegetables' (NH) was derived from a food frequency questionnaire (validated instrument in 2001, but adapted) and combines the results from two questions: 'How often do you eat fruit?' and 'How often do you eat vegetables?' Respondents indicating 'once a day' for both questions are considered as 'daily consumers', all others as 'not daily consumers';

4. 'lack of leisure time physical activity' (PA ) was based on a question recommended by a WHO group of experts [30] 'What best describes your leisure time activities during the last year?', with the answer categories (two additional categories added to the validated instrument): 1) Hard training and competitive sport more than once a week, 2) Jogging and other recreational sports or gardening, at least 4 hours per week, 3) Jogging and other recreational sports or gardening, at most 4 hours per week, 4) Walking, bicycling or other light activities at least 4 hours a week, 5) Walking, bicycling or other light activities at most 4 hours a week and 6) Reading, watching TV or other sedentary activities, taking the last answer category (yes, lack =1) versus the other answer categories (no lack $=2$ ).
The questions on nutritional habits were included in the face-to-face questionnaire while the questions on the use of alcohol and tobacco were included in the selfadministered questionnaire. The question on leisure time physical activity was first included in the face-toface questionnaire (1997 and 2001) and later moved to the self-administered questionnaire (2004 and 2008).

Detailed information on educational attainment was collected from the face-to-face questionnaire and recoded into four educational categories, as proposed by the Organisation for Economic Co-operation and Development (OECD) [31]: no or primary education, secondary inferior, secondary superior and tertiary education. Educational attainment was assessed at household level and defined as the highest educational degree of the reference person or his/her partner.

The evolution over time of obesity in the three regions was assessed by using a logistic regression to calculate the Odds Ratio (OR) and the 95\% confidence intervals (95\% CI) of being obese, adjusted for age, gender and education (proxy for socio-economic status, a potential confounder [1,2,32-35]), with the Belgian population of 2001 as reference. A description of these (background) variables was given through the crude prevalence.

The effect of the selected lifestyle factors was first explored by presenting crude prevalence by year and region. Logistic regression, stratified by region, allowed examining if adjustment for lifestyle factors added to a model with age, gender, education and year could explain the different regional trends. In a next step interactions between year and lifestyle factors were separately added to the complete model. If a significant interaction was found, this was further explored through models including the specific lifestyle indicator, age, gender and education, and stratified by year and region.

All the analyses were performed with $\mathrm{SAS}^{\oplus} 9.2$ [36] and the SURVEYLOGISTIC procedure was used to take into account the complex survey design (weighting, clustering and stratification). As item non-response was limited, a complete-case analysis was performed.

\section{Results}

Table 1 describes the distribution of the crude prevalence of the background variables (age, gender, educational level, year and region). This table also shows that the prevalence of obesity significantly increased up to the age group 55-64 years (OR 6.7, 95\% CI 5.0-9.1), with decreasing educational level (OR that is 2.6 higher, 95\% CI 2.2-3.0 for those with no or primary education than for those with a tertiary education) and from the first survey in 1997 (reference) to the fourth in 2008 (OR 1.3, 95\% CI 1.1-1.5). Furthermore, a significant higher prevalence of obesity was observed in the Walloon Region (OR 1.3, 95\% CI 1.2-1.5) compared to the Flemish Region. Adding the interaction year"region to this model 
Table 1 Crude prevalence $(95 \% \mathrm{CI})$ and odds of being obese $(95 \% \mathrm{CI})$, HIS, Belgium 1997-2008

\begin{tabular}{|c|c|c|c|}
\hline Variables & & $\%(95 \% \mathrm{Cl})$ & Odds $(95 \% \mathrm{Cl})$ \\
\hline \multirow[t]{7}{*}{ Age group } & $18-24$ years & $3.4(2.5-4.3)$ & 1 \\
\hline & 25-34 years & $6.6(5.8-7.4)$ & $2.177(1.589-2.982)$ \\
\hline & $35-44$ years & $11.9(10.8-12.9)$ & $4.105(3.039-5.544)$ \\
\hline & $45-54$ years & $14.6(13.4-15.8)$ & $4.946(3.686-6.637)$ \\
\hline & $55-64$ years & $20.1(18.5-21.6)$ & $6.733(4.988-9.090)$ \\
\hline & $65-74$ years & $17.9(16.3-19.6)$ & $5.227(3.846-7.105)$ \\
\hline & $75+$ years & $13.4(11.7-15.0)$ & $3.365(2.442-4.638)$ \\
\hline \multirow[t]{2}{*}{ Gender } & Males & $11.9(11.3-12.6)$ & 1 \\
\hline & Females & $12.8(12.2-13.5)$ & $1.063(0.974-1.160)$ \\
\hline \multirow[t]{4}{*}{ Education } & No or primary education & $19.0(17.5-20.5)$ & $2.581(2.226-2.992)$ \\
\hline & Secondary inferior & $16.8(15.5-18.1)$ & $2.273(1.974-2.616)$ \\
\hline & Secondary superior & $12.6(11.7-13.5)$ & $1.797(1.580-2.044)$ \\
\hline & Tertiary education & $7.4(6.8-8.1)$ & 1 \\
\hline \multirow[t]{4}{*}{ Year } & 1997 & $10.8(9.8-11.9)$ & 1 \\
\hline & 2001 & $12.1(11.2-13.0)$ & $1.067(0.926-1.229)$ \\
\hline & 2004 & $12.7(11.7-13.6)$ & $1.155(1.001-1.033)$ \\
\hline & 2008 & $13.8(12.7-14.8)$ & $1.307(1.131-1.512)$ \\
\hline \multirow[t]{3}{*}{ Region } & Flemish Region & $11.5(10.8-12.2)$ & 1 \\
\hline & Brussels Region & $11.1(10.4-11.9)$ & $1.065(0.956-1.186)$ \\
\hline & Walloon Region & $14.5(13.7-15.3)$ & $1.329(1.205-1.466)$ \\
\hline
\end{tabular}

reveals that the evolution in the Walloon Region $(\mathrm{P}=$ $0.0367)$ was significantly different from the one in the Flemish Region: while the prevalence of obesity remained stable in the Walloon Region, an increase could be observed in the Flemish Region.

Table 2 presents the distribution of the crude prevalence of the lifestyle factors. In summary, for all but daily drinking alcohol, the selected lifestyle factors seem to improve over time in every region.

Table 3 shows that, after adjustment for age, gender, education and year, daily drinking alcohol was not associated with obesity in the Flemish Region, which contrasted to the findings of the Brussels and the Walloon Regions with lower odds of being obese in daily alcohol drinkers (respectively OR 0.7, 95\% CI 0.5-0.9 and OR 0.8, 95\% CI 0.6-0.9). The odds of being obese was significantly lower among current smokers in the Flemish (OR 0.7, 95\% CI 0.6-0.8) and the Walloon Regions (OR 0.7, 95\% CI 0.6$0.9)$, but this was not the case in the Brussels Region. Eating daily fruit and vegetables was not associated with obesity. A lack of leisure time physical activity increased significantly the odds of being obese in all regions: OR of 1.6 (95\% CI 1.3-1.8) and 1.6 (95\% CI 1.4-1.9) in respectively the Brussels and the Flemish Region. In the Walloon Region this OR was even 1.8 (95\% CI 1.6-2.1).

Table 4 indicates that significant interactions were observed between year and lifestyle indicators only in the
Table 2 Crude prevalence $(95 \% \mathrm{CI})$ by lifestyle factor ${ }^{\&}$, year and region, HIS, Belgium 1997-2008

\begin{tabular}{ccccc}
\hline & Year & Flemish Region & Brussels Region & Walloon Region \\
\hline AL & 1997 & $6.5(5.3-7.7)$ & $8.6(7.1-10.1)$ & $9.6(7.7-11.4)$ \\
& 2001 & $8.5(7.4-9.6)$ & $13.0(11.3-14.7)$ & $10.6(9.2-12.0)$ \\
& 2004 & $8.1(7.0-9.3)$ & $11.7(10.1-13.3)$ & $10.6(9.1-12.1)$ \\
& 2008 & $11.3(9.8-12.8)$ & $11.3(9.7-12.9)$ & $13.6(11.8-15.5)$ \\
TA & 1997 & $24.1(21.9-26.2)$ & $27.0(24.5-29.6)$ & $27.5(25.1-29.9)$ \\
& 2001 & $22.9(21.1-24.7)$ & $25.4(23.2-27.6)$ & $26.0(24.0-28.0)$ \\
& 2004 & $22.6(20.6-24.6)$ & $23.8(21.4-26.1)$ & $25.7(23.5-27.9)$ \\
& 2008 & $18.7(16.7-20.6)$ & $22.3(20.0-24.6)$ & $24.0(21.6-26.4)$ \\
NH & 1997 & $22.2(20.0-24.4)$ & $20.3(17.9-22.6)$ & $27.4(24.9-29.9)$ \\
& 2001 & $46.9(44.5-49.2)$ & $36.3(33.8-38.8)$ & $39.8(37.4-42.1)$ \\
& 2004 & $44.9(42.6-47.2)$ & $41.8(39.2-44.4)$ & $39.5(37.0-42.0)$ \\
& 2008 & $60.2(57.8-62.6)$ & $53.9(51.4-56.4)$ & $54.6(52.2-57.1)$ \\
PA & 1997 & $28.8(26.4-31.1)$ & $41.2(38.2-44.2)$ & $38.8(35.9-41.8)$ \\
& 2001 & $29.3(27.2-31.5)$ & $38.2(35.8-40.6)$ & $42.6(40.2-44.9)$ \\
& 2004 & $20.8(19.0-22.6)$ & $27.0(24.6-29.5)$ & $31.7(29.3-34.1)$ \\
& 2008 & $22.2(20.1-24.2)$ & $30.9(28.3-33.5)$ & $34.9(32.3-37.4)$ \\
\hline a
\end{tabular}

${ }^{\circledR}$ Lifestyle factors: daily drinking alcohol (AL), current smoking (TA), eating daily fruit and vegetables (NH) and lack of leisure time physical activity (PA). 
Table 3 Odds $(95 \% \mathrm{Cl})$ of being obese, stratified by region, HIS, Belgium 1997-2008

\begin{tabular}{|c|c|c|c|}
\hline \multirow{2}{*}{$\begin{array}{l}\text { Region } \\
\text { Flemish Region }\end{array}$} & \multicolumn{2}{|l|}{ Variables } & \multirow{2}{*}{$\begin{array}{r}\text { Odds }(\mathbf{9 5 \%} \mathrm{Cl}) \\
1.017(1.013-1.021\end{array}$} \\
\hline & Age & - & \\
\hline & \multirow[t]{2}{*}{ Gender } & Males & 1 \\
\hline & & Females & $1.021(0.893-1.168)$ \\
\hline & \multirow[t]{4}{*}{ Education } & No or primary & $1.913(1.502-2.436)$ \\
\hline & & Secondary inferior & $2.349(1.888-2.923)$ \\
\hline & & Secondary superior & $1.724(1.415-2.101)$ \\
\hline & & Tertiary & 1 \\
\hline & Year & - & $1.038(1.017-1.059)$ \\
\hline & \multicolumn{2}{|c|}{ Daily drinking alcohol } & $0.901(0.699-1.161)$ \\
\hline & \multicolumn{2}{|c|}{ Current smoking } & $0.692(0.577-0.829)$ \\
\hline & \multicolumn{2}{|c|}{ Eating daily fruit and vegetables } & $0.956(0.825-1.107)$ \\
\hline & \multicolumn{2}{|c|}{ Lack of leisure time physical activity } & $1.631(1.400-1.899)$ \\
\hline \multirow[t]{12}{*}{ Brussels Region } & Age & - & $1.010(1.007-1.014)$ \\
\hline & \multirow[t]{2}{*}{ Gender } & Males & 1 \\
\hline & & Females & $0.934(0.803-1.087)$ \\
\hline & \multirow[t]{4}{*}{ Education } & No or primary & $3.140(2.516-3.919)$ \\
\hline & & Secondary inferior & $1.603(1.274-2.018)$ \\
\hline & & Secondary superior & $1.622(1.310-2.009)$ \\
\hline & & Tertiary & 1 \\
\hline & Year & - & $1.038(1.016-1.061)$ \\
\hline & \multicolumn{2}{|c|}{ Daily drinking alcohol } & $0.662(0.496-0.883)$ \\
\hline & \multicolumn{2}{|c|}{ Current smoking } & $0.836(0.682-1.026)$ \\
\hline & \multicolumn{2}{|c|}{ Eating daily fruit and vegetables } & $0.956(0.810-1.129)$ \\
\hline & \multicolumn{2}{|c|}{ Lack of leisure time physical activity } & $1.556(1.313-1.844)$ \\
\hline \multirow[t]{12}{*}{ Walloon Region } & Age & - & $1.011(1.007-1.015)$ \\
\hline & \multirow[t]{2}{*}{ Gender } & Males & 1 \\
\hline & & Females & $0.824(0.723-0.938)$ \\
\hline & \multirow[t]{4}{*}{ Education } & No or primary & $2.085(1.663-2.614)$ \\
\hline & & Secondary inferior & $1.875(1.530-2.298)$ \\
\hline & & Secondary superior & $1.748(1.452-2.105)$ \\
\hline & & Tertiary & 1 \\
\hline & Year & - & $1.012(0.995-1.030)$ \\
\hline & \multicolumn{2}{|c|}{ Daily drinking alcohol } & $0.749(0.595-0.941)$ \\
\hline & \multicolumn{2}{|c|}{ Current smoking } & $0.732(0.621-0.862)$ \\
\hline & \multicolumn{2}{|c|}{ Eating daily fruit and vegetables } & $1.064(0.932-1.216)$ \\
\hline & \multicolumn{2}{|c|}{ Lack of leisure time physical activity } & $1.795(1.562-2.063)$ \\
\hline
\end{tabular}

Walloon Region. This was the case for daily alcohol consumption $(P=0.0136)$ and leisure time physical activity $(P=0.0145)$. Those interactions were further illustrated in Tables 5 and 6. In the Walloon Region no significant association was found between obesity and daily drinking alcohol in the first three survey years. Conversely, in 2008 obesity was significantly less prevalent among daily alcohol users than among non-drinkers (OR 0.5, 95\% CI 0.3-0.8). In all regions and almost for all surveyed years there was a strong and significant association between being obese and being physical inactive during leisure time. However, only in the Walloon Region this association dropped substantially between 1997 (OR 2.6, 95\% CI 1.9-3.6) and 2008 (OR 1.4, 95\% 1.1-1.8).

\section{Discussion}

In view of the increasing obesity problem that is reported worldwide, the stabilisation of obesity in the Walloon 
Table 4 Obesity: interactions 'year*lifestyle indicator \&, (P-value) added to Table 3, stratified by region, HIS, Belgium 1997-2008

\begin{tabular}{lccc}
\hline Interaction & Flemish Region & Brussels Region & Walloon Region \\
\hline+ year*AL & 0.2104 & 0.9290 & 0.0136 \\
+ year*TA & 0.2898 & 0.0543 & 0.3714 \\
+ year* $\mathrm{NH}$ & 0.3132 & 0.2743 & 0.0888 \\
+ year*PA & 0.9546 & 0.9102 & 0.0145 \\
\hline
\end{tabular}

\& Lifestyle indicators: daily drinking alcohol (AL), current smoking (TA), eating daily fruit and vegetables (NH) and lack of leisure time physical activity (PA).

${ }^{*} *$ indicated the interaction between two variables.
Region is quite remarkable. When investigating the association of lifestyle factors influencing obesity (stratified by region), the lack of leisure time physical activity appears to be the most important determinant throughout all regions. The core findings of this study are that a) in the Walloon Region, the association between leisure time physical activity and obesity has significantly decreased during the study period and b) in contrast to the Flemish and Brussels Regions, the prevalence of obesity did not significantly increase in the Walloon Region.

From our analyses it appears that the increase in prevalence of people that are physical active during leisure time cannot entirely explain the stabilisation of the

Table 5 Odds $(95 \% \mathrm{CI})$ of being obese and $\mathrm{AL}^{\&}$, stratified by region and year, HIS, Belgium 1997-2008

\begin{tabular}{|c|c|c|c|c|c|}
\hline Year & Variables & & Flemish Region & Brussels Region & Walloon Region \\
\hline \multirow[t]{8}{*}{1997} & Age & & $1.025(1.015-1.034)$ & $1.012(1.003-1.021)$ & $1.023(1.014-1.032)$ \\
\hline & Gender & Males & 1 & 1 & 1 \\
\hline & & Females & $0.951(0.678-1.334)$ & 1.367 (0.969-1.928) & $0.756(0.565-1.012)$ \\
\hline & Education & No or primary & $2.713(1.529-4.815)$ & $3.370(1.862-6.099)$ & $1.484(0.870-2.533)$ \\
\hline & & Secondary inferior & $2.042(1.204-3.465)$ & $2.137(1.290-3.542)$ & $1.355(0.877-2.094)$ \\
\hline & & Secondary superior & $2.259(1.404-3.636)$ & $1.308(0.772-2.213)$ & $1.536(1.035-2.277)$ \\
\hline & & Tertiary & 1 & 1 & 1 \\
\hline & $\mathrm{AL}$ & & $1.139(0.657-1.973)$ & $0.825(0.336-2.025)$ & $0.893(0.543-1.470)$ \\
\hline \multirow[t]{8}{*}{2001} & Age & & $1.023(1.016-1.031)$ & $1.009(1.002-1.015)$ & $1.016(1.010-1.023)$ \\
\hline & Gender & Males & 1 & 1 & 1 \\
\hline & & Females & $1.125(0.874-1.449)$ & $0.940(0.708-1.246)$ & 0.969 (0.759-1.238) \\
\hline & Education & No or primary & $2.256(1.406-3.620)$ & $2.878(1.934-4.284)$ & $3.229(2.167-4.811)$ \\
\hline & & Secondary inferior & $2.969(1.944-4.534)$ & $1.148(0.709-1.860)$ & $2.234(1.519-3.286)$ \\
\hline & & Secondary superior & $1.749(1.169-2.617)$ & $1.765(1.177-2.647)$ & $2.254(1.552-3.275)$ \\
\hline & & Tertiary & 1 & 1 & 1 \\
\hline & $\mathrm{AL}$ & & $1.085(0.666-1.767)$ & $0.488(0.294-0.811)$ & $0.892(0.581-1.370)$ \\
\hline \multirow[t]{8}{*}{2004} & Age & & $1.022(1.015-1.029)$ & $1.015(1.009-1.021)$ & $1.014(1.008-1.020)$ \\
\hline & Gender & Males & 1 & 1 & 1 \\
\hline & & Females & $1.141(0.887-1.466)$ & $1.168(0.879-1.552)$ & $0.887(0.696-1.130)$ \\
\hline & Education & No or primary & $1.785(1.173-2.718)$ & $3.762(2.563-5.522)$ & $2.458(1.617-3.736)$ \\
\hline & & Secondary inferior & $2.112(1.414-3.156)$ & $1.878(1.249-2.825)$ & $2.858(1.972-4.141)$ \\
\hline & & Secondary superior & $1.462(1.009-2.118)$ & $1.505(1.009-2.246)$ & $2.226(1.540-3.217)$ \\
\hline & & Tertiary & 1 & 1 & 1 \\
\hline & $\mathrm{AL}$ & & $0.565(0.344-0.930)$ & $0.708(0.425-1.180)$ & $0.833(0.533-1.254)$ \\
\hline \multirow[t]{8}{*}{2008} & Age & & $1.015(1.008-1.022)$ & $1.011(1.004-1.018)$ & 1.009 (1.003-1.016) \\
\hline & Gender & Males & 1 & 1 & 1 \\
\hline & & Females & $1.144(0.900-1.453)$ & $0.678(0.513-0.896)$ & $1.010(0.794-1.284)$ \\
\hline & Education & No or primary & $1.529(0.956-2.444)$ & $3.401(2.279-5.078)$ & $2.075(1.414-3.044)$ \\
\hline & & Secondary inferior & $2.447(1.657-3.613)$ & $1.667(1.066-2.608)$ & $1.732(1.179-2.546)$ \\
\hline & & Secondary superior & $1.611(1.139-2.279)$ & $1.971(1.344-2.891)$ & $1.498(1.082-2.072)$ \\
\hline & & Tertiary & 1 & 1 & 1 \\
\hline & $\mathrm{AL}$ & & $0.855(0.543-1.348)$ & $0.728(0.452-1.172)$ & $0.497(0.312-0.790)$ \\
\hline
\end{tabular}


Table 6 Odds $(95 \% \mathrm{CI})$ of being obese and PA ${ }^{\text {\& }}$, stratified by region and year, HIS, Belgium 1997-2008

\begin{tabular}{|c|c|c|c|c|c|}
\hline Year & Variables & & Flemish Region & Brussels Region & Walloon Region \\
\hline \multirow[t]{8}{*}{1997} & Age & & $1.024(1.014-1.033)$ & $1.010(1.001-1.020)$ & $1.016(1.007-1.025)$ \\
\hline & Gender & Males & 1 & 1 & 1 \\
\hline & & Females & $0.901(0.644-1.260)$ & $1.311(0.926-1.856)$ & $0.679(0.501-0.921)$ \\
\hline & Education & No or primary & $2.483(1.394-4.423)$ & $3.027(1.716-5.338)$ & $1.226(0.707-2.126)$ \\
\hline & & Secondary inferior & $1.896(1.118-3.214)$ & $1.895(1.136-3.158)$ & $1.134(0.729-1.764)$ \\
\hline & & Secondary superior & $2.169(1.349-3.489)$ & $1.235(0.732-2.081)$ & $1.412(0.953-2.093)$ \\
\hline & & Tertiary & 1 & 1 & 1 \\
\hline & PA & & $1.632(1.151-2.313)$ & $1.860(1.287-2.687)$ & $2.627(1.900-3.632)$ \\
\hline \multirow[t]{8}{*}{2001} & Age & & $1.022(1.015-1.030)$ & $1.006(0.999-1.013)$ & $1.014(1.008-1.020)$ \\
\hline & Gender & Males & 1 & 1 & 1 \\
\hline & & Females & $1.091(0.840-1.416)$ & $0.968(0.726-1.292)$ & $0.922(0.726-1.171)$ \\
\hline & Education & No or primary & $2.140(1.330-3.446)$ & $2.993(2.005-4.468)$ & $3.064(2.048-4.584)$ \\
\hline & & Secondary inferior & $2.874(1.881-4.393)$ & $1.188(0.739-1.909)$ & $2.097(1.423-3.090)$ \\
\hline & & Secondary superior & $1.752(1.172-2.618)$ & $1.825(1.217-2.738)$ & $2.132(1.460-3.115)$ \\
\hline & & Tertiary & 1 & 1 & 1 \\
\hline & PA & & $1.356(1.027-1.791)$ & $1.121(0.828-1.518)$ & $1.594(1.241-2.047)$ \\
\hline \multirow[t]{8}{*}{2004} & Age & & $1.020(1.013-1.027)$ & $1.013(1.007-1.019)$ & $1.012(1.006-1.018)$ \\
\hline & Gender & Males & 1 & 1 & 1 \\
\hline & & Females & $1.132(0.880-1.456)$ & $1.147(0.863-1.525)$ & $0.848(0.667-1.079)$ \\
\hline & Education & No or primary & $1.768(1.165-2.683)$ & $3.638(2.476-5.346)$ & $2.248(1.472-3.434)$ \\
\hline & & Secondary inferior & $2.133(1.423-3.197)$ & $1.774(1.167-2.699)$ & $2.727(1.876-3.963)$ \\
\hline & & Secondary superior & $1.467(1.012-2.127)$ & $1.423(0.959-2.111)$ & $2.144(1.494-3.075)$ \\
\hline & & Tertiary & 1 & 1 & 1 \\
\hline & PA & & $1.668(1.247-2.232)$ & $1.904(1.367-2.653)$ & $1.749(1.316-2.324)$ \\
\hline \multirow[t]{8}{*}{2008} & Age & & $1.013(1.006-1.020)$ & $1.009(1.003-1.016)$ & $1.006(1.000-1.013)$ \\
\hline & Gender & Males & 1 & 1 & 1 \\
\hline & & Females & $1.121(0.882-1.425)$ & $0.666(0.504-0.881)$ & 1.029 (0.809-1.307) \\
\hline & Education & No or primary & $1.429(0.890-2.294)$ & $3.438(2.303-5.131)$ & $2.057(1.397-3.027)$ \\
\hline & & Secondary inferior & $2.345(1.576-3.490)$ & $1.649(1.317-2.875)$ & $1.694(1.149-2.498)$ \\
\hline & & Secondary superior & $1.546(1.096-2.180)$ & $1.946(1.317-2.875)$ & $1.480(1.068-2.051)$ \\
\hline & & Tertiary & 1 & 1 & 1 \\
\hline & PA & & $1.708(1.274-2.290)$ & $1.479(1.053-2.078)$ & $1.354(1.050-1.747)$ \\
\hline
\end{tabular}

\&PA: lack of leisure time physical activity.

obesity prevalence. An assumption could be that an improvement of leisure time physical activity among obese people in the Walloon Region could possibly also be associated with a healthier lifestyle in general. This could not be investigated in this study. Although this is less distinct, our results indicate that in the Walloon Region the association between daily alcohol drinking and obesity has changed over time. Surprisingly, daily drinking alcohol seems to have a positive impact on obesity. The value of this indicator is however limited as the quantity of alcohol consumed was not taken into account.

The National Health Interview Survey is a powerful tool due to its horizontal approach of data collection: information on the health status (i.e. BMI), sociodemographic background characteristics and lifestyle factors are collected at the same time for the same person. Furthermore, it includes a large sample of the general population [37]. Because participation in this survey is not compulsory, the response rate is rather low. This problem was experienced in all the survey years [13]. The survey method and most of the questions have remained relatively unchanged over time. Even though the questions related to alcohol drinking and the daily consumption of fruit and vegetables are an exception to this rule, as they slightly changed between 1997 and 2008, it is assumed that this had no impact on the principal findings of our 
research. A possible artefact could be associated to the question concerning leisure time physical activity which in the first two surveys was included in the face-to-face questionnaire and later moved to the self-reported questionnaire. If this is the case, the artifact would have been identified equally throughout the regions.

However, some shortcomings of the data should be highlighted. The indicator 'eating daily fruit and vegetables' is the only one of the food pallet. Other eating habits, such as fat or sugar consumption, could have a bigger influence on bodyweight. Unfortunately the number of food frequency questions included in the survey is limited, resulting in a lack of details about the dietary habits. The nutritional indicator that we used has several facets which can also be applied for other lifestyle factors. Our choice of the lifestyle indicators is partly based on the availability of the data from the four surveyed years. The choice of these indicators could have an influence on the study results. In addition, self-reported questions on behaviors such as alcohol consumption, smoking, diet and physical habits are subject to a social desirability; the prevalence of a lack of leisure time physical activity is probably underestimated. A more reliable method to measure physical activity would have been to rely on accelerometers, but this technique is expensive and therefore not applicable to large population surveys [38]. In summary, it is possible that the available lifestyle data inadequately reflected the lifestyle dimensions that had an impact on the different regional time trends of obesity.

Although the BMI is a valuable tool to provide a standardized definition of obesity for the purposes of national surveillance and international comparisons [39], it has some drawbacks, especially when height and weight are self-reported. Studies have highlighted that when calculating the BMI via self-reported data, obesity will be underestimated because overweight participants tend to understate their weight and all participants tend to overreport their height $[2,5,8,9]$. Underestimation of obesity is also related to the fact that obese people more often refuse to take part in surveys [1]. Moreover, the use of the BMI does not take into account the body fatness and body fat distribution which are associated with obesity comorbidities $[8,9,20]$. Although the BMI measurement through self-reported data is biased, it is unlikely that this bias substantially changes over time. Consequently the assumption that the evolution of obesity via self-reported BMI yields reasonable valid results is quite plausible.

Current physical activity levels in the three Belgian regions are still far too low to efficiently counterbalance the prevalence of obesity. Even though the study is unable to link the campaigns to promote physical activity to the prevention of obesity, these campaigns have existed during the studied period and differed by region (in Belgium health promotion and prevention is primarily dealt with at the regional level). In the period 2002-2006, the Flemish Region launched a campaign with the main purpose to strengthen self-esteem (feeling good as you are). The second wave of this campaign focused on healthy and active lifestyle, to improve the quality of life (2003) and on healthy nutrition (2004). Physical activity was a specific target only in 2003. After 2008, the Flemish Region dedicated its campaign to improve physical activity, along with healthy nutrition. It will consequently be interesting to verify the results of the next health survey conducted in 2013. On the other hand, the campaign in the Walloon and the Brussels Regions during 2005-2010 was promoting healthy habits, including both nutrition and physical activity. This campaign was launched after the health survey of 2004.

Epidemiological research has shown clear health gains through staying active, which has already been understood by scientists and academics, but not by the policy makers. Promoting physical activity by the governments is still far less a priority than that of other lifestyle factors, such as smoking and nutrition. Encouraging people to be physically active has numerous benefits that go beyond weight control. A number of psychological benefits have been identified, with the clearest being depression and anxiety [40]. Obesity can be prevented with lifestyle changes involving increased physical activity $[1,3,5,7,14,18,19]$. Promoting physical activity has therefore to remain a priority. Regular and adequate levels of physical activity - at least an hour a day - is important to keep a steady weight, or even reduce it, and to fight the obesity epidemic. Consequently, a healthy weight will have a positive effect on the health outcomes $[23,41]$.

\section{Conclusion}

The decreasing association between obesity and a lack of leisure time physical activity in the Walloon Region between 1997 and 2008 could indicate that there is an increasing awareness of risk factors for obesity in the Walloon population, which may have resulted in a more favourable evolution of the obesity epidemic in Wallonia than in the two other regions.

\section{Competing interests \\ The authors declared that they have no competing interests.}

\section{Authors' contribution}

SDr drafted the paper. JVdH and SD helped with the interpretation of the data. JVdH, SD and JT reviewed and commended the manuscript. All authors approved the final and submitted version.

\section{Acknowledgements}

The HIS is a project financed by and conducted on request of all Ministers responsible for Public Health at the federal, regional and communal level united in the Commission of Commissioners of the HIS. Thanks to Anna Roy for revising the English language.

Received: 16 September 2013 Accepted: 12 March 2014

Published: 2 June 2014 


\section{References}

1. Zaninotto P, Head J, Stamatakis E, Wardle H, Mindell J: Trends in obesity among adults in England from 1993 to 2004 by age and social class and projections of prevalence to 2012. J Epidemiol Community Health 2009, 63:140-146.

2. Baum CL II, Ruhm CJ: Age, socioeconomic status and obesity growth. $J$ Health Econ 2009, 28:635-648.

3. Mokdad AH, Bowman BA, Ford ES, Vinicor F, Marks JS, Koplan JP: The continuing epidemics of obesity and diabetes in the United States. JAMA 2001, 286:1195-1200.

4. Dastgiri S, Mahdavi R, TuTunchi H, Faramarzi E: Prevalence of obesity, food choices and socio-economic status: a cross-sectional study in the north-west of Iran. In Public Health Nutr 2006, 9:996-1000.

5. Mokdad AH, Ford ES, Bowman BA, Dietz WH, Vinicor F, Bales VS, Marks JS: Prevalence of obesity, diabetes, and obesity-related health risk factors, 2001. JAMA 2003, 289:76-79.

6. World Health Organization: Obesity: Preventing and Managing The Global Epidemic, Technical Report Series 854. Geneva, Switzerland: World Health Organization; 2011:1-452

7. Wild S, Roglic G, Green A, Sicree R, King H: Global prevalence of diabetes Estimates for the year 2000 and projections for 2030. In Diabetes Care 2004, 27:1047-1053.

8. Cámara AD, Spijker JJA: Super size Spain? A cross-sectional and quasi-cohort trend analysis of adult overweight and obesity in an accelerated transition country. In J Biosoc Sci 2010, 42:377-393.

9. Paeratakul S, Lovejoy JC, Ryan DH, Bray GA: The relation of gender, race and socioeconomic status to obesity and obesity comorbidities in a sample of US adults. In Int J Obesity 2002, 26:1205-1210.

10. Shields M, Carroll MD, Ogden CL: Adult obesity prevalence in Canada and the United States. NCHS Data Brief 2011, 56:1-8

11. Zhang $Q$, Wang Y: Socioeconomic inequality of obesity in the United States: do gender, age, and ethnicity matter? In Soc Sci Med 2004, 58:1171-1180

12. Increasing incidence of type 2 diabetes in the third millennium: Is abdominal fat the central issue? In Diabetes Care 2000, 23:441-442.

13. Charafeddine R, Demarest S, Drieskens S, Gisle L, Tafforeau J, Van de Heyden J: Highlights of the Belgian Health Interview survey 2008. Brussels: WIV-ISP; 2012.

14. Shaw JE, Chisholm DJ: Epidemiology and prevention of type 2 diabetes and the metabolic syndrome. In MJA 2003, 179:379-383.

15. Mokdad AH, Ford ES, Bowman BA, Nelson DE, Engelgau MM, Vinicor $F$ Marks JS: Diabetes trends in the U.S.: 1990-1998. Diabetes Care 2000 23:1278-1283.

16. Steps to health: A European framework to promote physical activity for health. In WHO Regional Office for Europe. Copenhagen, Denmark: EUR/06/ 5062700/10; 2007:1-48

17. World Health Organization: WHO Technical Report Series 894. Geneva, Switzerland: World Health Organization; 2000:1-253.

18. Astrup A: Healthy lifestyles in Europe: prevention of obesity and type II diabetes by diet and physical activity. Public Health Nutr 2001, 4:499-515

19. Hossain P, Kawar B, El Nahas M: Obesity and diabetes in the developing world - a growing challenge. In N Engl J Med 2007, 356:213.

20. Apfelbacher CJ, Cairns J, Bruckner T, Möhrenschlager M, Behrendt H, Ring J, Krämer U: Prevalence of overweight and obesity in East and West German children in the decade after reunification: population-based series of cross-sectional studies. In J Epidemiol Community Health 2008, 62:125-130.

21. Kaleta D, Makowiec-Dabrowska T, Jegier A: Occupational and leisure-time energy expenditure and body mass index. Int J Occup Med Environ Health 2007, 20:9-16.

22. Gutiérrez-Fisac JL, Guallar-Castillón P, Diez-Ganan L, López Garcia E, Banegas Banegas F, Rodriguez Artelejo F: Work-related physical activity is Not associated with body mass index and obesity. Obes Res 2002, 10:270-276.

23. Seo DC, Li K: Leisure-time physical activity dose-response effects on obesity among US adults: results from the 1999-2006 National Health and Nutrition Examination Survey. J Epidemiol Community Health 2010, 64:426-431.

24. Gaziano JM: Fifht phase of the epidemiologic transition: the age of obesity and inactivity. In JAMA 2010, 303:275-276.

25. Schröder H, Morales-Molina JA, Bermejo S, Barral D, Mándoli ES, Grau M, Guxens M, de Jaime Gil E, Alvarez MD, Marrugat J: Relationship of abdominal obesity with alcohol consumption at population scale. Eur J Nutr 2007, 46:369-376.

26. Khosla T, Lowe CR: Obesity and smoking habits. BMJ 1971, 4:10-13.

27. Chatkin R, Mottin CC, Chatkin JM: Smoking among morbidly obese patients. BMC Pulm Med 2010, 10:61.

28. Demarest S, Van der Heyden J, Charafeddine R, Drieskens S, Gisle L, Tafforeau J: Methodological basics and evolution of the Belgian Health Interview Survey 1997-2008. Arch Public Health 2013, 71:24.

29. Demarest S: Méthodologie. In Enquête de santé, 2008. Etat de santé. Edited by Van Der Heyden J, Gisle L, Demarest S, Drieskens S, Hesse E, Tafforeau J. Bruxelles: ISP - Direction Opérationelle Santé Publique et Surveillance; 2010:31-44

30. de Bruin A, Picavet HS, Nossikov A: Health Interview Surveys: towards international harmonization of methods and instruments. Copenhagen: World Health Organisation; 1996.

31. UNESCO: International Standard Classification of Education, ISCED 1997. Montreal, Canada: UNESCO, Institute for Statistics; 1997:1-31.

32. Singh-Manoux A, Gourmelen J, Lajnef M, Sabia S, Sitta R, Menvielle G, Melchior M, Nabi H, Lance UL, Guéguen A, Lert F: Prevalence of educational inequalities in obesity between 1970 and 2003 in France. Obes Rev 2009, 10(5):511-518.

33. Ogden $\mathrm{CL}$, Lamb MM, Carroll MD, Flegal KM: Obesity and Socioeconomic Status in Adults: United States. In NCHS Data Brief 2010, 50:1-8.

34. McLaren L: Socioeconomic status and obesity. In Epidemiologic Rev 2007, 29:29-48.

35. Demarest S, Drieskens S, Gisle L, Van Der Heyden J, Tafforeau J: Enquête de santé, 2008. In Rapport V - Les Inégalités Socio-Economiques En Matière De Santé. Edited by Direction Opérationelle Santé publique et surveillance. 2032-9180. Brussels: Institut Scientifique de Santé Publique; 2010:1-367.

36. SAS Institute: SAS/STAT ${ }^{\oplus} 9.2$ User's Guide. Cary, NC: SAS Institute Inc; 2008

37. Drieskens S, Van Oyen H, Demarest S, Van der Heyden J, Gisle L, Tafforeau J: Multiple risk behaviour: increasing socio-economic gap over time? In Eur J Publ Health 2010, 20:634-639.

38. Luke A, Dugas LR, Durazo-Arvizu RA, Cao G, Cooper RS: Assessing physical activity and its relationship to cardiovascular risk factors: NHANES 2003-2006. BMC Public Health 2011, 11:387.

39. Flegal KM, Carroll MD, Ogden CL, Curtin LR: Prevalence and trends in obesity among US adults. JAMA 2008, 2010:303. doi: 10.1001/jama.2009.2014.

40. Kim YS, Park YS, Allegrante JP, Marks R, Ok H, Cho KO, Ok Cho K, Garber CE: Relationship between physical activity and general mental health. Prev Med 2012, 55:458-463.

41. Jakicic JM, Otto AD: Physical activity considerations for the treatment and prevention of obesity. Am J Clin Nutr 2005, 82(suppl):226S-229S.

doi:10.1186/2049-3258-72-18

Cite this article as: Drieskens et al:: Is the different time trend (1997-2008) of the obesity prevalence among adults in the three Belgian regions associated with lifestyle changes? Archives of Public Health 2014 72:18.

\section{Submit your next manuscript to BioMed Central and take full advantage of:}

- Convenient online submission

- Thorough peer review

- No space constraints or color figure charges

- Immediate publication on acceptance

- Inclusion in PubMed, CAS, Scopus and Google Scholar

- Research which is freely available for redistribution 